\title{
The Helicobacter pylori flbA flagellar biosynthesis and regulatory gene is required for motility and virulence and modulates urease of $H$. pylori and Proteus mirabilis
}

\author{
DAVID J. McGEE, CHRISTOPHER COKER*, TRACI L. TESTERMAN, JANETTE M. HARRO*, \\ SUSAN V. GIBSON† and HARRY L. T. MOBLEY*
}

Departments of Microbiology \& Immunology and $\uparrow$ Comparative Medicine, University of South Alabama College of Medicine, Mobile, AL 36688 and *Department of Microbiology \& Immunology, University of Maryland School of Medicine, Baltimore, MD 21201, USA

\begin{abstract}
Helicobacter pylori and Proteus mirabilis ureases are nickel-requiring metallo-enzymes that hydrolyse urea to $\mathrm{NH}_{3}$ and $\mathrm{CO}_{2}$. In both $\mathrm{H}$. pylori and in an Escherichia coli model of $\mathrm{H}$. pylori urease activity, a high affinity nickel transporter, NixA, is required for optimal urease activity, whereas the urea-dependent UreR positive transcriptional activator governs optimal urease expression in $P$. mirabilis. The $H$. pylori flbA gene is a flagellar biosynthesis and regulatory gene that modulates urease activity in the $E$. coli model of $\boldsymbol{H}$. pylori urease activity. All $\boldsymbol{f l b A}$ mutants of eight strains of $\boldsymbol{H}$. pylori were non-motile and five had a strain-dependent alteration in urease activity. The $f l b A$ gene decreased urease activity 15 -fold when expressed in $E$. coli containing the $H$. pylori urease locus and the nix $A$ gene; this was reversed by disruption of $f b A$. The $f l b A$ gene decreased $n i x A$ transcription. $f b A$ also decreased urease activity three-fold in $E$. coli containing the $P$. mirabilis urease locus in a urea- and UreR-dependent fashion. Here the $f b A$ gene repressed the $P$. mirabilis urease promoter. Thus, FlbA decreased urease activity of both $H$. pylori and $P$. mirabilis, but through distinct mechanisms. $H$. pylori wild-type strain SS1 colonised gerbils at a mean of $5.4 \times 10^{6} \mathrm{cfu} / \mathrm{g}$ of antrum and caused chronic gastritis and lesions in the antrum. In contrast, the $f b A$ mutant did not colonise five of six gerbils and caused no lesions, indicating that motility mediated by $f l b A$ was required for colonisation. Because FlbA regulates flagellar biosynthesis and secretion, as well as forming a structural component of the flagellar secretion apparatus, two seemingly unrelated virulence attributes, motility and urease, may be coupled in $\boldsymbol{H}$. pylori and $P$. mirabilis and possibly also in other motile, ureolytic bacteria.
\end{abstract}

\section{Introduction}

Helicobacter pylori causes gastritis [1], is strongly associated with the development of peptic ulcers [2] and constitutes a risk factor for gastric adenocarcinoma $[3,4]$. The mechanisms behind the development of these diseases are not well understood.

Urease, which catalyses the hydrolysis of urea to $\mathrm{CO}_{2}$ and $\mathrm{NH}_{4}{ }^{+}$, is central to the pathogenesis of $H$. pylori infection

Received 6 March 2002; revised version accepted 17 June 2002.

Corresponding author: Dr D. J. McGee (e-mail:dmcgee@ jaguar1.usouthal.edu). and urease-negative mutants fail to colonise various animal models [5-7]. Because urease is a nickel-requiring enzyme, nickel transporters, such as NixA, are required for full urease activity in both $H$. pylori [8] and in an Escherichia coli model of $H$. pylori urease $[9,10]$. $H$. pylori urease was thought initially to be constitutively expressed $[11,12]$, but mounting evidence suggests otherwise. Recently, a number of genes, including a flagellar biosynthesis and regulatory gene, $f l b A$, was demonstrated to modulate urease activity [9]. Furthermore, urease protein levels [13] and activity [14, 15] are elevated under acidic conditions and nickel has been shown to activate $H$. pylori urease expression transcriptionally [16]. Thus, H. pylori may modulate urease activity in vivo in response to specific environmental cues. 
Proteus mirabilis causes urinary tract infections including pyelonephritis and kidney stone formation, particularly in patients with indwelling catheters or structural abnormalities of the urinary tract [17-19]. Like H. pylori, the urease of $P$. mirabilis is required for virulence [20]. However, in contrast with $H$. pylori, $P$. mirabilis urease is activated transcriptionally by UreR [21] in the presence of urea [22]; no UreR homologues exist in the $H$. pylori genome $[23,24]$, and $H$. pylori urease is not urea-inducible [25]. UreR is transcribed from its own promoter and then activates the divergently transcribed ureDABCEFG urease operon [21]. E. coli carrying the $P$. mirabilis urease gene cluster also has urease activity that is inducible by urea [22] and requires UreR [26], but optimal urease activity does not require addition of a nickel transporter gene, as it does in E. coli containing the $H$. pylori urease gene cluster. Urea-induced expression of the $P$. mirabilis urease (ureD) promoter-lacZ transcriptional fusion is likewise dependent on a functionally intact UreR [26]. Clearly, P. mirabilis urease is regulated differently from that of $H$. pylori.

The $f b A$ gene, which modulates $H$. pylori urease activity, is a cytoplasmic membrane protein of $80 \mathrm{kDa}$ of the LcrD protein family that is thought to be a structural component of the flagellar secretion apparatus $[9,27,28]$. Although much in-vitro data suggest that FlbA homologues are involved in virulence [2933], these have not been assessed in vivo for virulence. $H$. pylori motility is required for colonisation of gnotobiotic piglets [34,35], mice [36] and gerbils [37]. However, in the gerbil study, undefined and nonisogenic non-motile variants of $H$. pylori were employed. Thus, no specific $H$. pylori flagellar biosynthesis gene has been tested for its role in virulence in the gerbil model.

A previously described isogenic $A l b A$ mutant of one strain of $H$. pylori had both loss of motility and elevated urease activity in a qualitative assay [27], and another study indicated that $f b A$ significantly decreased urease activity and protein levels in $E$. coli containing the $H$. pylori urease gene cluster and the nixA nickel transporter gene (on pHP8080) [9]. New matters were generated by these studies. For example, urease activity and motility have not been quantified in $A b A$ mutants of $H$. pylori, nor has the effect of $f l b A$ on urease of other motile bacterial species, such as $P$. mirabilis, been addressed. Furthermore, the in-vivo relevance of $f l b A$ homologues has not been demonstrated. The present study examined these matters.

\section{Materials and methods}

Bacterial strains, growth conditions, primers and plasmids

H. pylori strains (Table 1) were grown at $37^{\circ} \mathrm{C}$ on Campylobacter blood agar (CBA) containing defibri- nated sheep blood $10 \% \mathrm{v} / \mathrm{v}$ in a $\mathrm{CO}_{2} 5 \%$ incubator with $100 \%$ humidity for 2 days. Alternatively, H. pylori was grown on F-12 agar or in F-12 broth containing fetal bovine serum 4\% [38]. Kanamycin $(5-20 \mu \mathrm{g} / \mathrm{ml})$ was added to the growth medium for selection and maintenance of transformants. E. coli and P. mirabilis strains (Table 1) were grown on Luria (L) agar and in $\mathrm{L}$ broth plus appropriate antibiotics at $37^{\circ} \mathrm{C}$. For urease assays with $E$. coli containing the $H$. pylori urease gene cluster on pHP8080, bacteria were grown in M9 minimal medium as described previously [9]. For urease assays with E. coli containing the P. mirabilis urease gene cluster on pMID1010, bacteria were grown in $\mathrm{L}$ broth to mid-log phase, and urea $(100 \mathrm{mM})$ was added to induce expression of the urease promoter in the presence of UreR $(1 \mathrm{~h})$. Cultures grown in the absence of urea served as uninduced controls. For $\beta$ galactosidase assays with the $H$. pylori urease or nixA promoters, $E$. coli strains were grown to mid-log phase in M9 minimal medium. For $\beta$-galactosidase assays with the $P$. mirabilis urease promoter, E. coli strains were grown in $\mathrm{L}$ broth to mid-log phase and urea $(100 \mathrm{mM})$ was added to induce urease promoter expression.

Oligonucleotide primers used for PCR and sequence analyses are listed in Table 1. Plasmids (detailed in Table 1) were constructed by standard molecular biology techniques $[39,40]$. Constructs were verified by restriction endonuclease digestions or PCR analyses, or both, and subsequently confirmed by sequence analysis of restriction endonuclease site junctions. Plasmids pBS- $f b A$, pBR322- $f l b A$ and their corresponding kanamycin disruption constructs are represented diagrammatically in Fig. 1.

\section{Motility assay}

Motility was assessed on F-12 soft agar. F-12 powder mix (Life Technologies) was reconstituted to a $2 \times$ stock, filter sterilised and mixed with an equal volume of Bacto agar $(0.7 \%)$. Fetal bovine serum was added to a final concentration of $4 \%$. Strains were inoculated by stabbing the agar and the plates were incubated at $37^{\circ} \mathrm{C}$ for several days in a $\mathrm{CO}_{2} \quad 5 \%$ incubator with $100 \%$ humidity. Strains were considered motile if they moved away from the initial stab within 2-3 days, whereas non-motile strains remained at the inoculation site.

\section{Construction and confirmation of H. pylori isogenic mutants of $\mathrm{flbA}$}

H. pylori strains were electroporated ( $800 \mathrm{ohms}, 2.5$ $\mathrm{kV}, 25 \mu \mathrm{F}$; Gene Pulser II, BioRad, Hercules, CA, USA) with insertionally inactivated $f b A$ to generate $f l b A 1$ mutants (derived from pBS- $f b A:: a p h A 3)$ or $f l b A 2$ mutants (derived from pBR322-flbA::aphA3) (Fig. 1 and Table 1). Two different $f l b A$ mutant constructs were employed to ensure reproducibility of the data. The kanamycin cassette was non-polar, thereby minimising 
Table 1. Oligonucleotide primers, plasmids and bacterial strains

\begin{tabular}{|c|c|c|c|c|}
\hline $\begin{array}{l}\text { Oligonucleotide } \\
\text { primers }\end{array}$ & \multicolumn{2}{|l|}{ Sequence $\left(5^{\prime}-3^{\prime}\right)$} & \multicolumn{2}{|l|}{ Remarks } \\
\hline FlhA-F1 & \multicolumn{2}{|c|}{$\begin{array}{l}\text { GCGCGGATCCGTGGCAAACGCCTTAATGAT } \\
\text { (BamHI site underlined) }\end{array}$} & \multicolumn{2}{|c|}{ Forward primer; upstream region of $H$. pylori flbA } \\
\hline FlhA-R1 & \multicolumn{2}{|c|}{$\begin{array}{l}\text { GCGCATCGATTGGTAAACTTGCATCATTCTCC } \\
\text { (ClaI site underlined) }\end{array}$} & \multicolumn{2}{|c|}{$\begin{array}{l}\text { Reverse primer; downstream of translational stop } \\
\text { codon of } H \text {. pylori flbA }\end{array}$} \\
\hline KanDM-F2 & \multicolumn{2}{|c|}{ GCGCGAGCTGTATGATTTTT } & \multicolumn{2}{|c|}{ Forward primer; $3^{\prime}$ end of aphA3 } \\
\hline KanDM-R2 & \multicolumn{2}{|c|}{ CCAATTCACTGTTCCTTGCAT } & \multicolumn{2}{|c|}{ Reverse primer; $5^{\prime}$ end of aphA3 } \\
\hline LacZ-R1 & \multicolumn{2}{|c|}{ TGTGCTGCAAGGCGATTAAG } & \multicolumn{2}{|c|}{$\begin{array}{l}\text { Reverse primer; } 5 \text { ' end of lacZ; used for sequence } \\
\text { confirmation of pRS415-ureAP and pLX2106- } \\
\text { nixAP }\end{array}$} \\
\hline NixA-F2 & \multicolumn{2}{|c|}{$\begin{array}{l}\text { TCCCCCGGGGGAGAAGGTTCAGCCCAACAAA } \\
\text { (SmaI site underlined) }\end{array}$} & \multicolumn{2}{|c|}{$5^{\prime}$ H. pylori nixA promoter primer } \\
\hline NixA-R2 & \multicolumn{2}{|c|}{$\begin{array}{l}\text { CGGGATCCCGCAATTTCACAACACGCCTTT } \\
\text { (BamHI site underlined) }\end{array}$} & \multicolumn{2}{|c|}{$3^{\prime} H$. pylori nixA promoter primer } \\
\hline UreDA-F1 & \multicolumn{2}{|c|}{$\begin{array}{l}\text { GCGAATTCGAAATACTTGCAAATCCTTTTGA } \\
\text { (EcoR1 site underlined) }\end{array}$} & \multicolumn{2}{|c|}{$5^{\prime} H$. pylori ureA promoter primer } \\
\hline UreDA-R1 & \multicolumn{2}{|c|}{$\begin{array}{l}\text { GCGGATCCTCTTTTGGGGTGAGTTTCATC } \\
\text { (BamHI site underlined) }\end{array}$} & \multicolumn{2}{|c|}{$3^{\prime} H$. pylori ureA promoter primer } \\
\hline Plasmids & Parent & Description & & $\begin{array}{l}\text { Source or } \\
\text { reference }\end{array}$ \\
\hline \multicolumn{2}{|l|}{$\begin{array}{l}\text { pBluescript II SK and KS (-) } \\
\text { pACYC184 }\end{array}$} & \multicolumn{2}{|c|}{$\begin{array}{l}\text { ColE1 ori; } \mathrm{Ap}^{\mathrm{r}} \text {; cloning vectors } \\
\text { p15A ori, } \mathrm{Cm}^{\mathrm{r}}, \mathrm{Tc}^{\mathrm{r}} ; \text { low copy cloning vector }\end{array}$} & $\begin{array}{l}\text { Stratagene } \\
\text { New England } \\
\text { Biolabs }\end{array}$ \\
\hline \multicolumn{2}{|l|}{ pBR322 } & \multicolumn{2}{|c|}{ ColE1 ori; $\mathrm{Ap}^{\mathrm{r}} ; \mathrm{Tc}^{\mathrm{r}}$; cloning vector } & $\begin{array}{l}\text { New England } \\
\text { Biolabs }\end{array}$ \\
\hline pKHKS303 & pBluescript II KS (-) & \multicolumn{2}{|c|}{$\begin{array}{l}\text { p15A ori } \mathrm{Cm}^{\mathrm{r}} \text {; low copy cloning vector with blue-white } \\
\text { screen }\end{array}$} & J. Kyle Hendricks \\
\hline pHP1 & pUC19 & \multicolumn{2}{|c|}{ ColE1 ori; $\mathrm{Ap}^{\mathrm{r}} ; \mathrm{Kn}^{\mathrm{r}} ;$ source of aphA3 non-polar cassette } & $\begin{array}{l}\text { H. Kleanthous, } \\
\text { Acambis }\end{array}$ \\
\hline pBS-Kan & pBluescript II SK (-) & \multicolumn{2}{|c|}{$\begin{array}{l}\text { 1.2-kb EcoRI aphA3 non-polar cassette from pHP1 } \\
\text { cloned into same site in pBluescript II SK (-) }\end{array}$} & This study \\
\hline pBS- $f l b A$ & pBluescript II SK (-) & \multicolumn{2}{|c|}{$\begin{array}{l}\text { ColE1 ori; } \mathrm{Ap}^{\mathrm{r}} ; \text { H. pylori } 2.4 \mathrm{~kb} \text { flbA gene including } \\
\text { promoter cloned into the Bam HI and ClaI sites of } \\
\text { pBluescript II SK (-) }\end{array}$} & 9 \\
\hline pBS- $f l b A:: a p h A 3(f b A 1)$ & $\mathrm{pBS}-f l b A$ & \multicolumn{2}{|c|}{$\begin{array}{l}\mathrm{Ap}^{\mathrm{r}} ; \mathrm{Kn}^{\mathrm{r}} ; f l b A \text { disrupted by insertion of blunted } 1.2-\mathrm{kb} \\
a p h A 3 \text { cassette from pHP1 into NheI site (bp } 727 \text { within } \\
f l b A \text { coding sequence) in pBS- } f l b A\end{array}$} & This study \\
\hline pBR322- $f l b A$ & pBR322 & \multicolumn{2}{|c|}{$\begin{array}{l}\text { PCR-amplified } 2.4-\mathrm{kb} f l b A \text { gene including promoter } \\
\text { (primers FlhA-F1 and FlhA-R1) from pBS- } f b A \text { using } \\
\text { Vent DNA polymerase and cloned into unique } S s p \text { I site } \\
\text { of pBR322 }\end{array}$} & This study \\
\hline pBR322-flbA::aphA3 (flbA2) & pBR322-flbA & \multicolumn{2}{|c|}{$\begin{array}{l}\text { flbA disrupted by insertion of the } 1.2-\mathrm{kb} \text { SmaI-HincII } \\
\text { aphA3 cassette from pBS-Kan into the unique SspI site } \\
\text { (bp } 669 \text { within } f b A \text { coding sequence) in pBR322- } f b A\end{array}$} & This study \\
\hline pMID1010 & pBR322 & $\begin{array}{l}\text { ColE1 ori, } \mathrm{Ap}^{\mathrm{r}} ; \mathrm{pBR} \\
\text { urease gene cluster }\end{array}$ & coding the entire $P$. mirabilis & 21 \\
\hline $\mathrm{p} \Delta \mathrm{R} 10 \mathrm{~b}$ ureD-lac $Z$ & pBluescript II SK (-) & $\begin{array}{l}\text { ColE1 ori; } \mathrm{Ap}^{\mathrm{r}} ; \text { ence } \\
\text { lacZ transcriptional } \mathrm{f}\end{array}$ & mirabilis ureR and a ureD- & 26 \\
\hline pCC038 & pKHKS303 & $\begin{array}{l}\text { p15A ori, } \mathrm{Cm}^{\mathrm{r}} ; 2.4-1 \\
\text { promoter from pBS- } f \\
\text { pKHKS303 }\end{array}$ & $\begin{array}{l}K p n \mathrm{I} f b A \text { gene including } \\
\text { ted to same sites in }\end{array}$ & This study \\
\hline pRS415 & pBR322 & ColE1 ori; $\mathrm{Ap}^{\mathrm{r}} ; 10.8$ & romoterless lacZYA & 62 \\
\hline pRS415-ureAP & pRS415 & $\begin{array}{l}\text { 651-bp PCR-amplifie } \\
\text { UreDA-R1) containin } \\
\text { as template, and clor } \\
\text { pRS415 (transcriptior }\end{array}$ & $\begin{array}{l}\text { ment (primers UreDA-F1 and } \\
\text { urease promoter, with pHP } 8080 \\
\text { o the BamHI/EcoRI sites of } \\
\text { ion) }\end{array}$ & This study \\
\hline pLX2106 & pACYC184 and pRS415 & $\begin{array}{l}\text { p15A ori } \mathrm{Cm}^{\mathrm{r}} ; 11.3 \\
\text { pRS415 cloned into } \\
\text { has BamHI and Sma }\end{array}$ & $\begin{array}{l}\text { romoterless lacZYA from } \\
\text { ind EcoRV sites in pACYC184; } \\
\text { ng sites upstream of lacZYA }\end{array}$ & $\mathrm{Xin} \mathrm{Li}$ \\
\hline pLX2106-nixAP & $\mathrm{pLX} 2106$ & $\begin{array}{l}\text { 606-bp PCR-amplifie } \\
\text { NixA-R2) containing } \\
\text { (contains nixA from } \\
\text { SmaI and BamHI sit }\end{array}$ & $\begin{array}{l}\text { ment (primers NixA-F2 and } \\
\text { ixA promoter from pUEF201 } \\
\text { ori strain } 43504 \text { ) cloned into } \\
\text { LX2106 (transcriptional fusion) }\end{array}$ & Susan Harrington \\
\hline pWSK29 & & pSC101 ori, $\mathrm{Ap}^{\mathrm{r}}$; lov & cloning vector; $5.4 \mathrm{~kb}$ & 63 \\
\hline pWSK29- $f b A$ & pWSK29 & $\begin{array}{l}\text { 2.4-kb BamHI and } C \\
\text { from pBS-flbA clone }\end{array}$ & $\begin{array}{l}A \text { gene including promoter } \\
\text { same sites in pWSK29 }\end{array}$ & This study \\
\hline pUEF201 & pBluescript II SK (-) & nixA-containing clone & H. pylori strain 43504 & 10 \\
\hline pHP8080 & pACYC184 & $\begin{array}{l}\text { H. pylori urease gen } \\
\text { UMAB41 and nixA }\end{array}$ & $\begin{array}{l}\text { er cloned from strain } \\
\text { from strain } 43504\end{array}$ & 9 \\
\hline & & & & continued overleaf \\
\hline
\end{tabular}


Table 1. (continued)

\begin{tabular}{|c|c|c|}
\hline Bacterial strains & Relevant genotype or description & $\begin{array}{l}\text { Source or } \\
\text { reference }\end{array}$ \\
\hline \multicolumn{3}{|l|}{ E. coli } \\
\hline $\mathrm{DH} 5 \alpha$ & $\begin{array}{l}\left.F^{-} \text {supE } 44, \Delta \text { lacU169 ( } \phi 80 \text { lacZ } \Delta M 15\right), \text { hsdR17, recAl, } \\
\text { endA1, gyrA96, thi-1, relA1 }\end{array}$ & $\begin{array}{l}\text { Bethesda Research } \\
\text { Laboratories }\end{array}$ \\
\hline MC1061 & $\begin{array}{l}\text { araD139, } \Delta(\text { ara-leu }) 7696, \Delta(\text { lac }) 174, \text { galU, galK, rpsL, } \\
\text { thi-1, hsdR2 }\left(\mathrm{r}_{\mathrm{k}}-\mathrm{m}_{\mathrm{k}}+\right), \text { mcrB1 }\end{array}$ & $\begin{array}{l}\text { American Type } \\
\text { Culture Collection }\end{array}$ \\
\hline SE5000 & $\begin{array}{l}\mathrm{F}^{-}, \operatorname{araD} 139, \Delta(\arg F-l a c) U 169, \text { rpsL }, \text { relA } 1, \text { pts } F 25, \\
r b s R, f l b B 5301, \operatorname{rec} A 56\end{array}$ & 64 \\
\hline \multicolumn{3}{|l|}{ P. mirabilis } \\
\hline HI4320 & Wild-type, pyelonephritis strain & 17 \\
\hline \multicolumn{3}{|l|}{ H. pylori } \\
\hline 26695 & Wild-type, genome sequenced, non-motile variant & 24 \\
\hline ATCC 43504 & Wild-type, type strain & $\begin{array}{l}\text { American Type } \\
\text { Culture Collection }\end{array}$ \\
\hline HPDJM17 & $\begin{array}{l}\text { Wild-type, clinical isolate obtained by biopsy from a } \\
\text { patient with suspected gastritis at the University of } \\
\text { Maryland Hospital, Baltimore, MD }\end{array}$ & This study \\
\hline $\mathrm{J} 68$ & Duodenal ulcer isolate, $\operatorname{cag}(-)$ & Richard Peek \\
\hline $\mathrm{J} 75$ & Gastritis isolate, $\operatorname{cag}(-)$ & Richard Peek \\
\hline $\mathrm{J} 166$ & Duodenal ulcer isolate, $\operatorname{cag}(+)$ & Richard Peek \\
\hline B194A & Gastritis isolate, $\operatorname{cag}(+)$ & Richard Peek \\
\hline SS1 & Wild-type mouse-adapted strain & Adrian Lee \\
\hline UMAB41 & $\begin{array}{l}\text { Wild-type, clinical isolate obtained by biopsy from a } \\
\text { patient with suspected gastritis at the University of } \\
\text { Maryland Hospital, Baltimore, MD }\end{array}$ & 45 \\
\hline
\end{tabular}

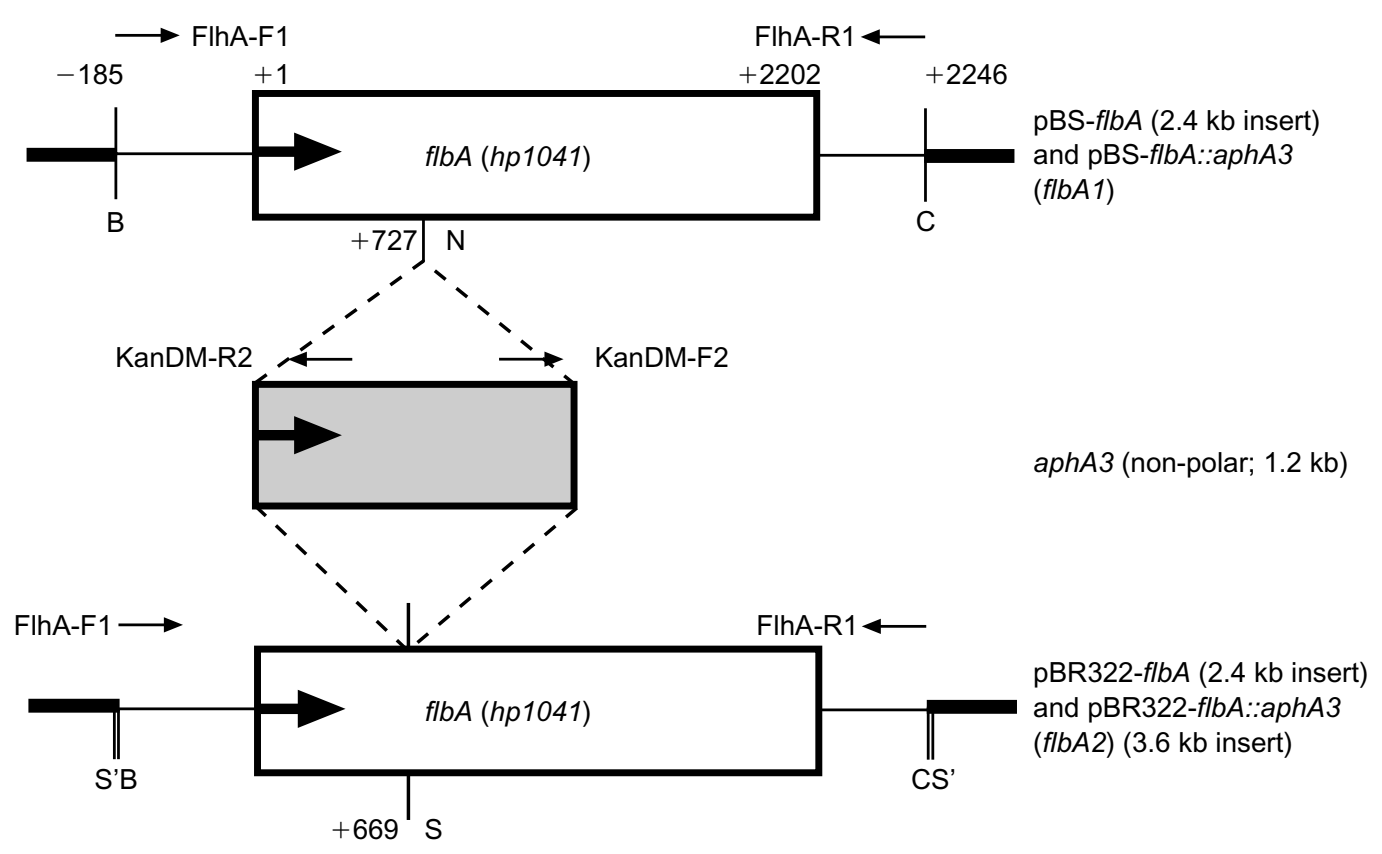

Fig. 1. $f b A$ constructs used. Plasmids pBS- $f b A$, pBS- $f b A:: a p h A 3$ (for generation of $f l b A 1$ mutants in $H$. pylori), pBR322-flbA and pBR322-flbA::aphA3 (for generation of $f l b A 2$ mutants in $H$. pylori) were constructed as indicated in Table 1. Large arrows, direction of transcription; small arrows, primers used for PCR confirmation of H. pylori flbA mutants; B, BamHI site; C, ClaI site; N, NheI site; S, SspI site; S', $S s p$ I site lost upon cloning; +1 refers to translation start site. The NheI and $S s p$ I sites within $f l b A$ were lost upon cloning of the blunted kanamycin resistance cassette.

effects on adjacent downstream genes. Chromosomal DNA was isolated [41] from kanamycin-resistant transformants and was used to re-transform wild-type strains to remove potential background mutations. Because $H$. pylori urease activity decreases significantly upon in-vitro passage (D. J. McGee and H. L. T. Mobley, unpublished observations), first-passage transformants were used for urease extracts and transformants were passaged a second time for isolation of chromosomal DNA and subsequent PCR-based con- firmation of mutants. The following PCR primer pairs were used (Table 1 and Fig. 1): FlhA-F1 and KanDMR2 (1.2-kb product only in mutants), FlhA-R1 and KanDM-F2 (1.8-kb product only in mutants), FlhA-F1 and FlhA-R1 (2.4-kb product in wild-type, 3.6-kb product in mutants). PCR conditions were: $94^{\circ} \mathrm{C}$ for 5 min (first cycle only), 30 cycles of $94^{\circ} \mathrm{C}$ for $60 \mathrm{~s}, 60^{\circ} \mathrm{C}$ for $90 \mathrm{~s}$ and $72^{\circ} \mathrm{C}$ for $90 \mathrm{~s}$, followed by extension for 5 min at $72^{\circ} \mathrm{C}$. The expected size product (or lack of product) was obtained in all cases (data not shown). 
Urease extract preparations, protein determinations and urease activity determinations

For H. pylori [42] or for E. coli containing the $H$. pylori urease gene cluster [9], extracts were prepared and protein concentration was determined as described. The phenol hypochlorite assay for urease activity was as described previously [9, 42]. For P. mirabilis or for $E$. coli containing the $P$. mirabilis urease gene cluster, extracts were prepared and measured for protein concentration and for urease activity by the phenol red urease assay as described previously [25].

\section{$\beta$-galactosidase activity determinations}

$E$. coli cells were grown to mid-exponential phase with appropriate antibiotics as described above. $\beta$-Galactosidase activity was determined by the method of Miller [43].

\section{Inoculation of gerbils, tissue processing and recovery of $H$. pylori}

Animal experiments were performed at the University of Maryland, with the approval of the Institute Animal Care and Use Committee. Male Mongolian gerbils (Meriones unguiculatus; Charles River) were inoculated twice orally (2 days apart) with $50 \mu \mathrm{l}$ of F12broth-grown $H$. pylori strains (SS1 background) suspended in sterile PBS ( $\mathrm{pH} 7.4)$ to $10^{9}$ viable $\mathrm{cfu} /$ ml. Control animals received PBS. At 4 weeks after infection, animals were anaesthetised (Avertin, $125 \mathrm{mg}$ / $\mathrm{kg}$ ), exsanguinated by cardiac puncture and euthanased by cervical dislocation. Stomachs were removed, dissected longitudinally along the greater curvature and washed several times in sterile PBS. The antrum was dissected into two halves. One was weighed and then homogenised (Ultra-Turrax T25, IKA Works.) in $1 \mathrm{ml}$ of sterile PBS. The other half was fixed in formalin $10 \%$ for histology. Antrum homogenates and dilutions of them in PBS were plated for viable counts in triplicate on CBA containing nalidixic acid $10 \mu \mathrm{g} / \mathrm{ml}$, vancomycin $10 \mu \mathrm{g} / \mathrm{ml}$, amphotericin B $2 \mu \mathrm{g} / \mathrm{ml}$, bacitracin $30 \mu \mathrm{g} / \mathrm{ml}$, polymyxin B $10 \mathrm{U} / \mathrm{ml}$ and trimethoprim $10 \mu \mathrm{g} / \mathrm{ml}$ to suppress normal flora.

\section{Histology}

Antrum sections were embedded in paraffin, sectioned $(5 \mu \mathrm{m})$, stained with haematoxylin and eosin and evaluated in a blind fashion.

\section{Statistical analysis of data}

Statistical analyses of urease and $\beta$-galactosidase activities were calculated by the alternative Welch's $t$ test; statistical analysis of colonisation data was made by the Mann-Whitney $t$ test. Instat 2.03 software (GraphPad Software, San Diego, CA, USA) was employed. $\mathrm{p}<0.05$ was considered statistically significant.

\section{Results \\ Effect of flbA on H. pylori motility}

To understand the role of $f b A$ in $H$. pylori motility, urease activity and virulence, $f b A$ mutants were generated in nine strains by two different strategies (Table 1, Fig. 1 and Materials and methods). All $f b A$ mutants tested in strain backgrounds SS1, UMAB41, 43504, HPDJM17, J68, J75, B194A and J166 were non-motile on F12-modified soft agar, in contrast to the corresponding wild-type strain. It was confirmed that wild-type strain 26695 was non-motile [44]; this strain could not be distinguished from the $f b A$ mutant in the soft agar assay. However, a revertant of wild-type strain 26695 , designated as $26695 \mathrm{~m}$, was isolated that was motile in the soft agar assay.

\section{Urease activity of $H$. pylori flbA mutants}

Eleven of $14 \mathrm{flbA}$ mutants of strain UMAB41 [45] and two of three $A b A$ mutants of strain 43504 had elevated urease activity compared with the corresponding wildtype strain (Fig. 2a and b, respectively; representatives shown). In contrast, $f l b A$ mutants of strains 26695 (21 of 31 mutants tested) and HPDJM17 (4 of 4 mutants tested), showed reduced urease activity (Fig. $2 \mathrm{c}$ and $\mathrm{d}$, respectively; representatives shown), whereas $f b A$ mutants of the fresh clinical isolate $\mathrm{J} 75$ had no detectable urease activity ( 2 of 2 mutants tested; Fig. 2e). Other strains of $H$. pylori containing the $f b A$ mutation exhibited no effect on urease activity: strain SS1 (3 of 3), fresh clinical isolates J68 (2 of 2), B194A (3 of 3), and J166 (3 of 3). The urease data were consistent regardless of the construct ( $f b A 1$ or $f l b A 2$ ) used to obtain the $A b A$ mutants. Two-thirds (42 of 65) of the $f b A$ mutants and five of nine $H$. pylori strain backgrounds showed changed urease activity, but whether this was an increase or decrease was clearly strain-dependent. Consistent data were obtained for wild-type and mutants of a single strain. The second observation from these experiments was that urease activity among wild-type $H$. pylori strains varied widely, ranging from 7000 units for strain 26695 to 55000 units for strain HPDJM17 (Fig. 2a-e).

H. pylori flbA effect on urease activity in E. coli containing genes for $H$. pylori urease and NixA nickel transporter

Because $f b A$ caused a strain-dependent modulation of urease activity in $H$. pylori, it would be difficult to decipher the reasons for the strain differences without extensive genetic characterisation of them. Therefore, an $E$. coli model of $H$. pylori urease activity was used, in which genetic variability could be minimised. In this model, the $H$. pylori urease gene cluster and the nixA 


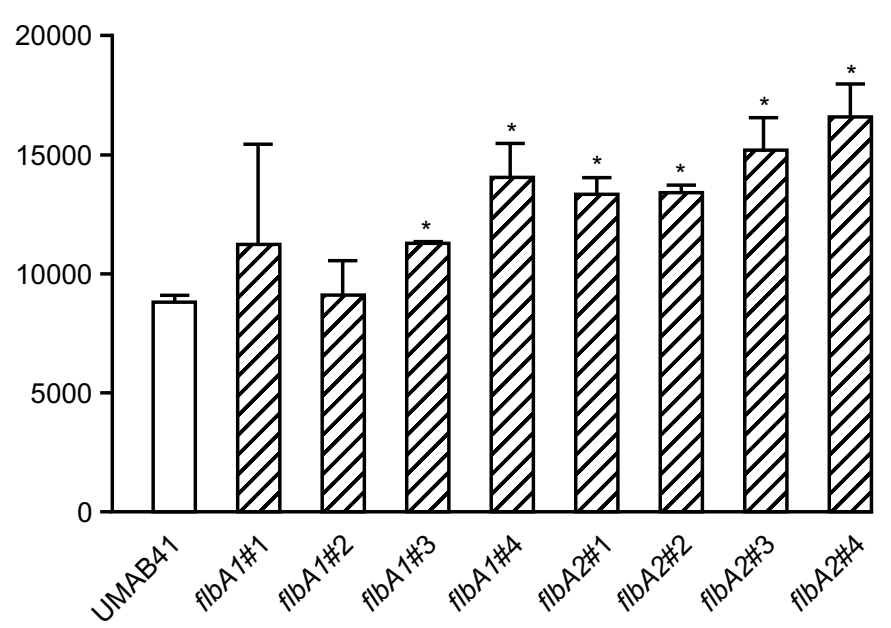

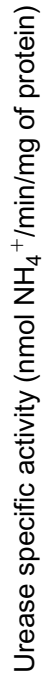

b

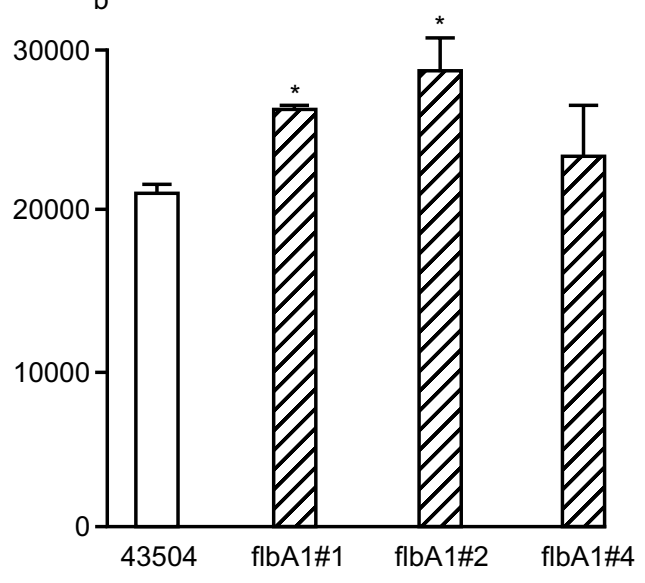

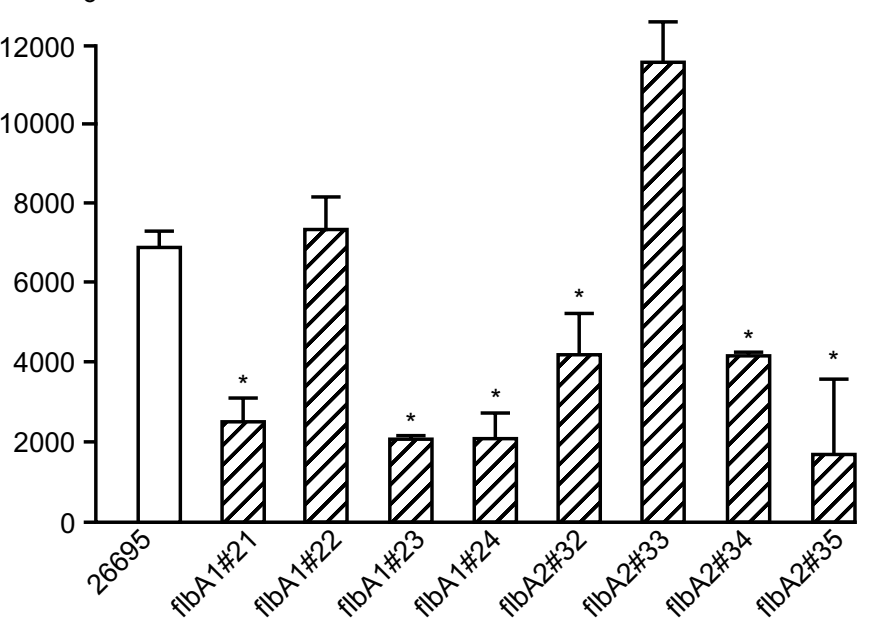

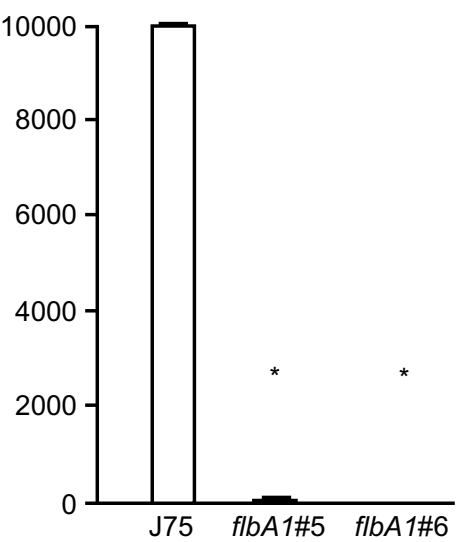

Fig. 2. Urease activity of wild-type and $f l b A$ mutants of $H$. pylori. Extracts of wild-type and isogenic $f b A$ mutants of blood agargrown $H$. pylori were measured for urease activity by the phenol-hypochlorite urease assay. Data are given as urease specific activity (nmol NH${ }_{4}^{+} / \mathrm{min} / \mathrm{mg}$ protein) and SD. Representative $f l b A$ mutants are shown, each of which was a separate transformant. \#Transformant number. *Except where noted, $\mathrm{p}<0.05$ compared with the corresponding wild-type strain. (a) Strain UMAB41 and isogenic $f l b A$ mutants. Data shown are duplicate or triplicate samples from one experiment representative of three. Each experiment was a separate transformation procedure. (b) Strain 43504 and isogenic $f l b A$ mutants. Data shown are duplicate or triplicate samples from one experiment. (c) Strain 26695 and isogenic $f l b A$ mutants. Data shown are duplicate or triplicate samples from one experiment representative of five. Each experiment was a separate transformation procedure. (d) Fresh clinical isolate HPDJM17 and isogenic $f l b A$ mutants. Data shown are duplicate or triplicate samples from one experiment. (e) Fresh clinical isolate J75 and isogenic $f b A$ mutants. Data shown are duplicate samples of two independent mutants from one experiment representative of two. Each experiment was a separate transformation procedure. $\mathrm{p}=0.0001$ between wild-type and $f b A$ mutant. 
nickel transporter gene were on plasmid pHP8080 and this permitted urease activity in $E$. coli [9]. The model allowed exploration of genes that affect urease or nix $A$ expression without the excessive variability observed with $H$. pylori. To investigate further the role of $f b A$ in modulating $H$. pylori urease activity, the $f b A$ gene was subcloned and the resultant plasmid (pBS- $f l b A$ ) DNA was transformed into $E$. coli (pHP8080). Urease activity was reduced 15 -fold compared with the vector control strain (Fig. 3). Disruption of $f l b A$ with a kanamycin resistance cassette restored urease activity in E. coli (pHP8080/pBS-flbA::aphA3) to levels of the vector control strain, E. coli (pHP8080/pBS) (Fig. 3). This suggested that $f l b A$ functioned as a ureasedecreasing factor in the $E$. coli model.

\section{Effect of flbA on the H. pylori urease promoter and on expression of the nixA promoter}

The $f l b A$ gene may decrease urease activity by decreasing promoter activity of urease or nixA within pHP8080, or by increasing turnover of urease subunits. It was shown previously that $f l b A$ decreased expression of the urease subunits UreA and UreB, supporting the increased turnover model [9]. To address the other two possibilities, $f b A$ was transformed into $E$. coli containing nixA promoter- or urease promoter-lac $Z$ transcriptional fusion plasmids (Table 1) and the resultant strains were assayed for $\beta$-galactosidase activity. $H$. pylori flbA had no effect on the $H$. pylori urease promoter in E. coli strain MC1061 containing pRS415ureAP (urease promoter-lacZ fusion) and pCC038 (Table 1; low copy plasmid harbouring $f b A$ ); the mean $\beta$-galactosidase activity was 1275 Miller Units in MC1061 (pRS415-ureAP/pCC038) versus 1529 Miller Units in the vector control strain, MC1061 (pRS415-

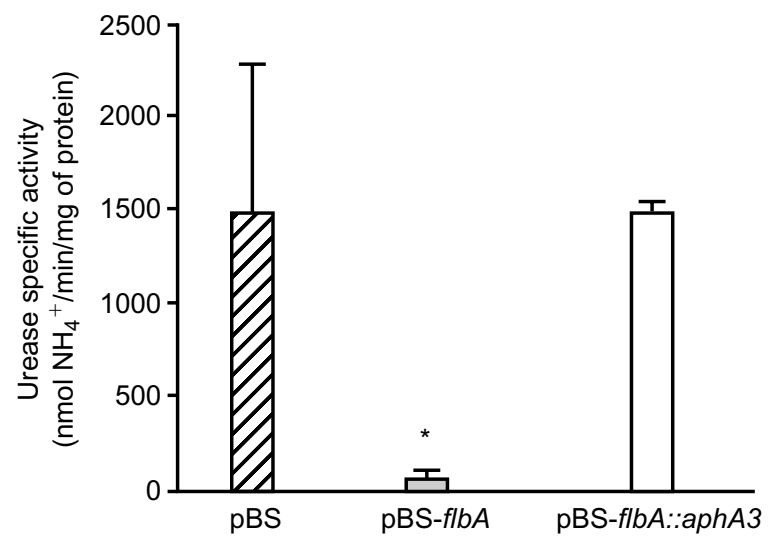

Fig. 3. Effect of $H$. pylori $f b A$ on urease activity in an E. coli model of $H$. pylori urease. E. coli strain SE5000 containing pHP8080 (H. pylori urease generating system) and the constructs listed in the figure were grown overnight in M9 minimal medium containing $1 \mu \mathrm{M}$ nickel chloride and urease activities of cytosolic extracts were determined by the phenol-hypochlorite urease assay. Data are given as urease specific activity (nmol $\mathrm{NH}_{4}{ }^{+} / \mathrm{min} / \mathrm{mg}$ of protein) and SD and are an average of at least three experiments each conducted in duplicate or triplicate. ${ }^{*} \mathrm{p}<0.0001$ compared with the vector control strain and with the $f b A:: a p h A 3$ vector-containing strain.
ureAP/pKHKS303) (p >0.05). Similarly, no differences were observed when the same constructs were transformed into $E$. coli strain DH5 $\alpha$. No $\beta$-galactosidase activity was observed when the $H$. pylori urease promoter was omitted from the construct (as plasmid pRS415). In contrast, the $f b A$ gene significantly decreased expression of the nixA promoter in $E$. coli MC1061 (pLX2106-nixAP) by about three-fold $(\mathrm{p}<0.0001)$ (Fig. 4). No $\beta$-galactosidase activity was observed when the $H$. pylori nixA promoter was omitted from the construct (as plasmid pLX2106).

\section{Effect of flbA on P. mirabilis urease activity in E. coli}

Because $f l b A$ decreased urease activity of some $H$. pylori strains, it was of interest to investigate the effect of $f b A$ on other bacterial ureases. The P. mirabilis urease was chosen as a model because urease regulation is well understood in this system [7]. The $P$. mirabilis urease gene cluster has a positive transcriptional activator of urease gene expression, UreR, which is divergently transcribed from the rest of the $u r e D A B C E F G$ urease gene cluster and activates transcription of itself and the ureDABCEFG operon only in the presence of urea. Plasmid pCC038, containing $f l b A$ in low copy, was transformed into $E$. coli DH5 $\alpha$ harbouring pMID1010, which encodes the entire $P$. mirabilis urease gene cluster. Transformants were grown in the presence of $100 \mathrm{mM}$ urea and assayed for urease activity. Urease activity was decreased seven-fold when compared with the vector control-containing strain, DH5 $\alpha$ (pKHKS303/ pMID1010) ( $<<0.001)$ (Fig. 5a). Only very low basal levels of urease activity were observed for both strains cultured in the absence of urea.

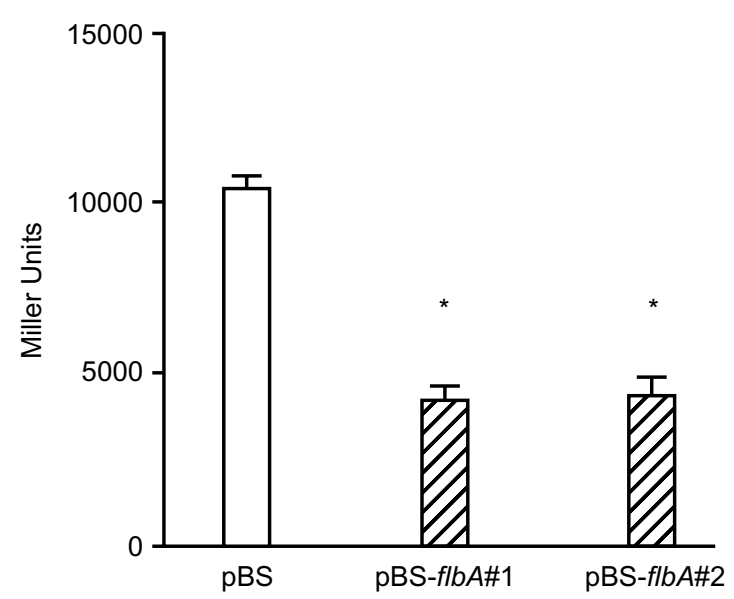

Fig. 4. Effect of $f b A$ on the nixA promoter by $\beta$-galactosidase assays in E. coli. E. coli strain MC1061 containing pLX2106nixAP plus either pBS or two independent, confirmed transformants containing pBS- $f b A$, were grown to mid-log phase in M9 minimal medium and $\beta$-galactosidase activity was determined. Data shown are representative of two experiments each conducted in triplicate. The average $\beta$-galactosidase activity in Miller Units and SD are shown. ${ }^{*} \mathrm{p}<0.0001$ compared with the vector control strain. \#Transformant number. 


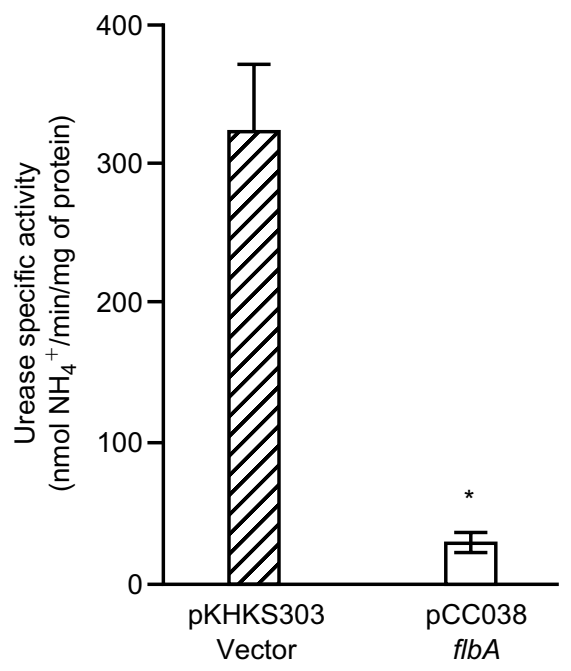

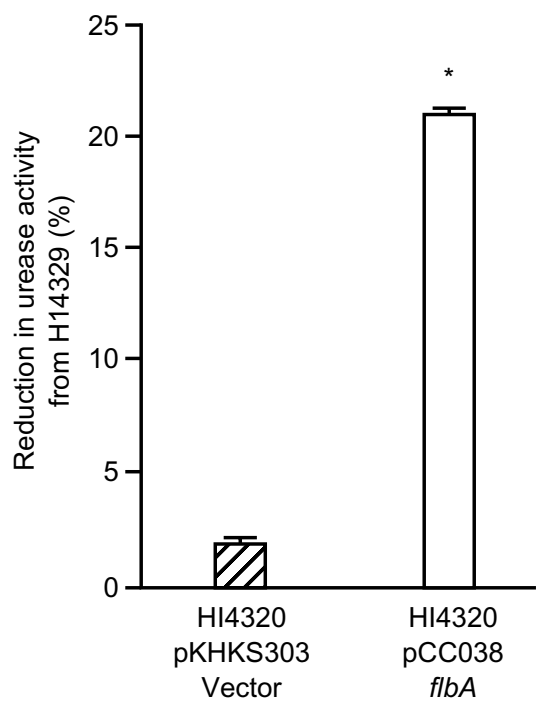

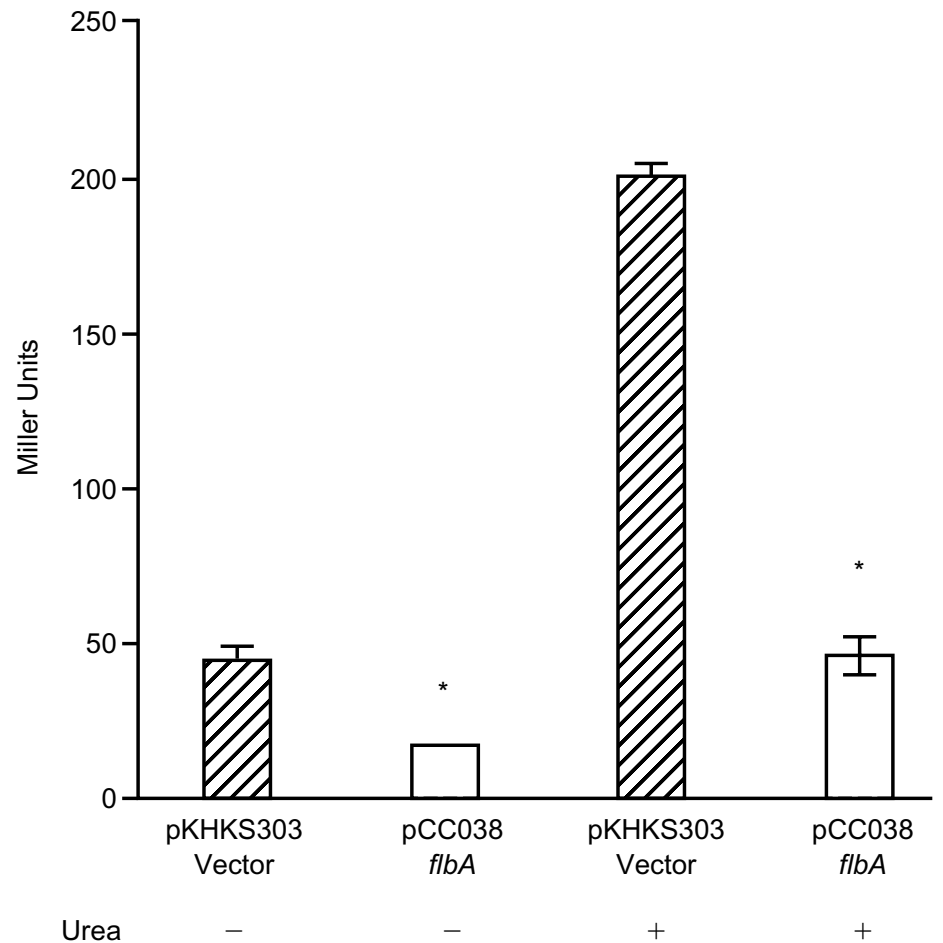

Fig. 5. Effect of $f b A$ on urease of P. mirabilis. (a) Effect of $f b A$ on urease activity of E. coli (pMID1010). E. coli strain DH5 $\alpha$ containing pMID1010 (P. mirabilis urease generating system) and the constructs listed in the figure were grown to mid-log phase in $\mathrm{L}$ broth and the urease promoter was induced by growth with $100 \mathrm{mM}$ urea for $1 \mathrm{~h}$, or left un-induced. Supernatant (cytosolic) extracts from French-pressed lysates were assayed for urease activity by the phenol red assay. Data shown are representative of six experiments each conducted in triplicate. The average urease activity and 2 SD are shown. ${ }^{*} \mathrm{p}<0.001$ compared with the vector control strain. (b) Effect of $f l b A$ on urease activity of P. mirabilis. P. mirabilis HI 4320 or HI4320 containing the constructs listed in the figure were grown and processed as described in Fig. 5a. Data shown are representative of three experiments each conducted in triplicate. Urease activity from vector-free HI4320 ( average $35000 \mathrm{nmol} \mathrm{N_{4 } +} / \mathrm{min} / \mathrm{mg}$ of protein) was set to $100 \%$. The percent decrease from vector-free HI4320 was calculated by the following formula: $100^{*}$ [(urease activity of vector-free HI4320) - (urease activity of vector-containing or $f b A$-containing HI4320)]/urease activity of vector-free HI4320. The average and 2 SD are shown. ${ }^{*} \mathrm{p}<0.001$ compared with HI4320 and with HI4320 (pKHKS303). (c) Effect of $f b A$ on the P. mirabilis urease promoter. $E$. coli strain $\mathrm{DH} 5 \alpha$ containing the $P$. mirabilis urease promoter (as construct $\mathrm{p} \Delta \mathrm{R} 10 \mathrm{~b} u r e D$-lacZ) and the constructs listed were grown as described in Fig. 5a and $\beta$-galactosidase activity was determined. Data shown are representative of three experiments each conducted in triplicate. The average $\beta$-galactosidase activity in Miller Units and 2 SD are shown. ${ }^{*} \mathrm{p}<0.001$ compared with the vector control strain. 


\section{Effect of flbA on urease activity in P. mirabilis HI4320}

When grown in the presence of $100 \mathrm{~mm}$ urea, $P$. mirabilis HI4320 (pCC038), which contains $\mathrm{AbA}$, produced $20 \%$ less urease activity than $P$. mirabilis containing the vector control, pKHKS303 (Fig. 5b). This suggested that the $f b A$ gene product of $H$. pylori repressed the expression of urease produced by $P$. mirabilis. Only very low basal levels of urease activity were observed for both strains when cultured in the absence of urea.

\section{Effect of flbA on P. mirabilis ureD promoter expression in E. coli}

To determine whether $A b A$ repressed the $P$. mirabilis urease promoter, plasmid pCC038 containing $A b A$ or the vector control, pKHKS303, was transformed into $E$. coli $\mathrm{DH} 5 a$ harbouring plasmid $\mathrm{p} \Delta \mathrm{R} 10 \mathrm{~b} u r e D-l a c Z$, which encodes the $P$. mirabilis ureD promoter transcriptionally fused to lacZYA [26]. This plasmid also has the functional ureR gene, which is required for expression of the ureD promoter. $\beta$-Galactosidase activity from urea-induced cultures of DH5 $\alpha$ (p $\Delta \mathrm{R} 10 \mathrm{bureD-lacZ/pCC038)}$ was decreased 4-5-fold ( $<<0.001$ ), as compared with the vector control strain, DH5 $\alpha$ (p $\Delta$ R10bureD-lacZ/pKHKS303) (Fig. 5c). Only nominal basal levels of $\beta$-galactosidase activity were detected in the uninduced controls grown in the absence of urea. This suggested that the $f b A$-mediated decrease of urease activity was dependent on urea and a functional UreR.

\section{Requirement for flbA for colonisation of gerbils by H. pylori}

Previous work based solely on in-vitro data has speculated that $f l b A$ homologues are important in virulence [29-33]. To determine whether $f b A$ was important for virulence in vivo, gerbils were inoculated with either wild-type $H$. pylori strain SS1, the isogenic $f b A$ mutant or sterile buffer. Of six animals inoculated with SS1, five were colonised with a mean of $5.4 \times 10^{6} \mathrm{cfu} / \mathrm{g}$ of antrum (Table 2 ). In contrast, only one of six animals inoculated with the $f b A$ mutant was colonised and this one animal had a mean of only $5.5 \times 10^{3} \mathrm{cfu} / \mathrm{g}$ of antrum, barely above the detection limit of $9 \times 10^{2} \mathrm{cfu} / \mathrm{g}$. Lack of colonisation by the $f b A$ mutant was not due to loss of urease activity, because the $f b A$ mutant of strain SS1 had wild-type urease activity. No H. pylori or Helicobacter-like organisms were recovered from animals inoculated with buffer alone. These results indicated that $f b A$ was required for H. pylori to colonise gerbils.

\section{Occurrence of chronic gastritis and ulcers in antral tissue from gerbils infected with wild-type H. pylori and the flbA mutant}

The antrum from gerbils inoculated with wild-type $H$. pylori strain SS1 exhibited micro-ulcer formation (three of six animals) (Fig. 6a), lymphoid follicle formation and lymphocytic infiltration (one of six animals) (Fig. $6 b$ ), disruption of the ordered gastric pit and glandular architecture (six of six animals) and small foci of necrosis. In contrast, the antra from gerbils inoculated with the $f b A$ mutant (six of six animals) (Fig. 6c) or sterile buffer (Fig. 6d) exhibited no lesions.

\section{Discussion}

H. pylori FlbA is a cytoplasmic membrane protein that is required for motility and virulence and acts as an urease-decreasing factor in E. coli models containing either the H. pylori or the P. mirabilis urease gene clusters. Although FlbA affects the urease of both human pathogens, the mechanisms are distinct due to dissimilarities in the regulation of the urease gene clusters (Table 3). For P. mirabilis, the urease gene cluster is activated by the transcriptional regulator UreR in the presence of urea and a high affinity nickel transporter is not required for optimal urease activity in the E. coli model (Table 3). When provided in trans, $H$. pylori flbA decreased urease activity in E. coli (pMID1010) - i.e., with the urease-generating system of P. mirabilis - and in wild-type P. mirabilis HI4320 in the presence of urea and UreR (Fig. 5a and b) by specifically repressing transcription from the $P$. mirabilis urease promoter (Fig. 5c). In contrast with $P$.

Table 2. Role of $H$. pylori $f b A$ in colonisation of gerbils

\begin{tabular}{|c|c|c|c|}
\hline \multicolumn{2}{|r|}{$\mathrm{SS} 1$} & \multicolumn{2}{|r|}{$f l b A$ mutant } \\
\hline Animal no. & mean cfu/g of antrum & Animal no. & mean $\mathrm{cfu} / \mathrm{g}$ of antrum \\
\hline 1 & $1.9 \times 10^{7}$ & 7 & $<9.0 \times 10^{2 *}$ \\
\hline 2 & $5.8 \times 10^{6}$ & 8 & $<9.0 \times 10^{2 *}$ \\
\hline 3 & $<9.0 \times 10^{2 *}$ & 9 & $<9.0 \times 10^{2 *}$ \\
\hline 4 & $1.2 \times 10^{6}$ & 10 & $<9.0 \times 10^{2 *}$ \\
\hline 5 & $1.9 \times 10^{3}$ & 11 & $<9.0 \times 10^{2 *}$ \\
\hline 6 & $6.8 \times 10^{6}$ & 12 & $5.5 \times 10^{3}$ \\
\hline Mean (SD) & $5.4 \times 10^{6}\left(7.3 \times 10^{6}\right)$ & Mean (SD) & $1.6 \times 10^{3}\left(1.9 \times 10^{3}\right)^{\dagger}$ \\
\hline
\end{tabular}

Animals were inoculated with either $H$. pylori wild-type strain SS1 or its isogenic $f b A$ mutant and antrum samples were processed as described in Materials and methods. Homogenised antrum samples were plated in triplicate.

* No H. pylori recovered. Limit of detection was $9 \times 10^{2} \mathrm{cfu} / \mathrm{g}$ of antrum

${ }^{\dagger} \mathrm{p}=0.027$ between wild-type SS1 and the $f b A$ mutant. 

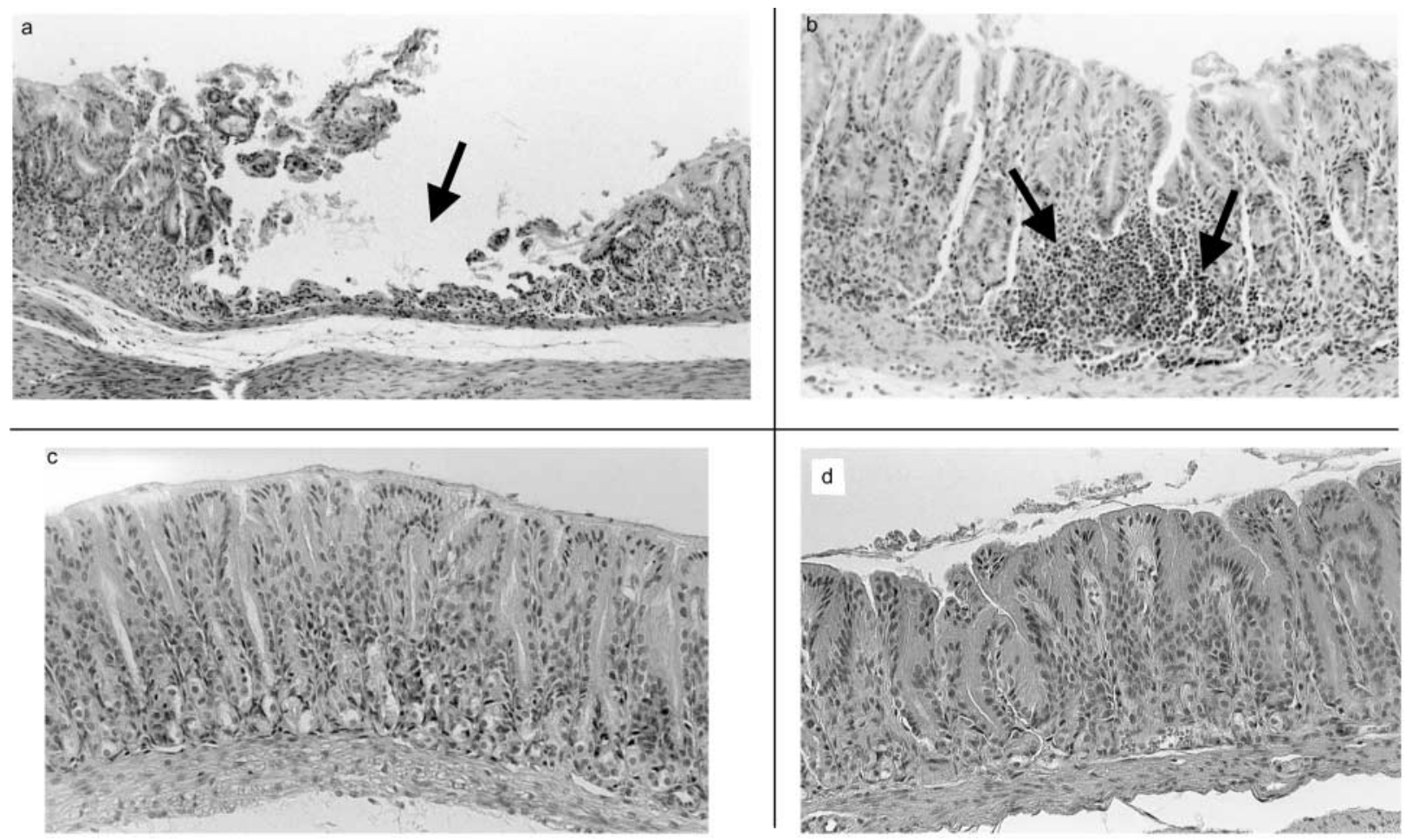

Fig. 6. Effect of $H$. pylori $f b A$ on histopathology in the antrum of gerbils. All sections ( $5 \mu \mathrm{m}$ thick) are antrum tissue of the stomach and were stained with haemotoxylin and eosin. Magnification, 180×. (a) Antrum from gerbils inoculated with wild-type H. pylori strain SS1. Arrow, micro-ulcer formation. (b) Antrum from gerbils inoculated with wild-type H. pylori. Arrow, lymphoid follicle formation and lymphocytic inflammation. (c) Antrum from gerbils inoculated with the $f b A$ mutant of $H$. pylori. (d) Antrum from gerbils inoculated with sterile buffer.

Table 3. Differences in urease properties and $f l b A$-mediated modulation of urease in $H$. pylori and P. mirabilis

\begin{tabular}{lllcll}
\hline Organism & Urease gene cluster & Urease regulation & $\begin{array}{l}\text { High affinity nickel } \\
\text { transporter required } \\
\text { for urease activity? }\end{array}$ & $\begin{array}{l}\text { Nickel concentration } \\
\text { in in-vivo niche }\end{array}$ & $\begin{array}{l}\text { Mechanism of FlbA- } \\
\text { mediated urease } \\
\text { modulation }\end{array}$ \\
\hline H. pylori & ureABIEFGH & FlbA, $\mathrm{pH}, \mathrm{NikR}$ & Yes & $\begin{array}{l}\text { Serum } / \text { gastric milieu: } \\
0.1-0.5 \mu \mathrm{g} / \mathrm{L}\end{array}$ & $\begin{array}{l}\text { NixA expression } \\
\text { repressed }\end{array}$ \\
P. mirabilis & ureRDABCEFG & $\begin{array}{l}\text { H-NS (repressor), UreR } \\
\text { urea (activator), FlbA } \\
\text { (repressor) }\end{array}$ & No & Urine: $1-3 \mu \mathrm{g} / \mathrm{L}$ & $\begin{array}{l}\text { Urease promoter } \\
\text { repressed }\end{array}$ \\
\hline
\end{tabular}

mirabilis urease, the $H$. pylori urease is not regulated by a UreR homologue nor by urea, but requires the NixA high affinity nickel transporter for urease activity in the E. coli model $[9,10]$ (summarised in Table 3). In the presence of $f b A$, urease activity was almost abolished in E. coli containing the $H$. pylori urease gene cluster (Fig. 3). However, this was not due to repression of the urease promoter as it was for $P$. mirabilis, but rather of the nixA promoter (Fig. 4). Because NixA is required for urease activity in the $E$. coli model of $H$. pylori urease, it is believed that the flbA-mediated decrease in $H$. pylori urease activity is due to decreased nixA expression, whereby less nickel would be delivered to apo-urease. This may render the protein more susceptible to proteolytic degradation and would explain the observation that the urease structural subunits UreA and UreB are markedly reduced in $E$. coli containing $f b A$ and pHP8080 [9].

The contrasting mechanisms of $f b A$-mediated modulation of urease in $H$. pylori and $P$. mirabilis may reflect the differences in the importance of a high affinity nickel transporter (Table 3) and the distinct niches that these two organisms occupy in vivo. H. pylori, which has very few regulatory genes [23,24], may exert regulatory control of gene expression through more subtle mechanisms than observed for organisms with larger genomes and more regulatory genes such as $P$. mirabilis. H. pylori is found in a very low nickel environment $(0.1-0.5 \mu \mathrm{g} / \mathrm{L}$ in serum and presumably in similar amounts in the gastric milieu [46-48]) and thus has evolved the high affinity nickel transporter nix $A$ for optimal delivery of nickel to apo-urease. In contrast, $P$. mirabilis resides in the urinary tract, where nickel concentrations are about 10-fold higher $(1-3 \mu \mathrm{g} / \mathrm{L}$ $[47,49])$ and thus a high affinity nickel transporter is unnecessary.

Although both $H$. pylori and P. mirabilis ureases were examined in $E$. coli models that were optimised for urease activity, urease activities in both models were significantly lower (10-30-fold for H. pylori urease, 
100-fold for $P$. mirabilis urease) than those observed in the native organisms, suggesting that additional loci and compounds are necessary to achieve peak urease activity. In support of this hypothesis, Soriano and Hausinger have shown that bicarbonate and GTP are needed to achieve high urease activities in an E. coli model of Klebsiella urease [50]. Furthermore, a previous study uncovered a number of genes, including $f b A$ and a putative DNA helicase, which influenced urease activity [9].

In addition to the evidence for decreased urease activity by $f b A$ in the $E$. coli models described above, evidence was also obtained that $f b A$ played a significant role in urease modulation in $H$. pylori itself. Some H. pylori $f l b A$ mutants in some strain backgrounds had elevated urease levels, whereas $f b A$ mutants of other strain backgrounds had a decrease or loss in urease activity (Fig. 2) [27]. This suggested that urease regulation differs among $H$. pylori isolates. This observation was complicated by the finding that $H$. pylori urease activity decreased (50-90\%, depending on the strain) by the tenth in-vitro passage in nearly all strains, regardless of whether $A b A$ was present or not (D. J. McGee and H. L. T. Mobley, unpublished observations). This problem was minimised by transforming DNA from $f b A$ mutants back into the wildtype strain to remove background mutations, and by measuring urease activity from first-passage transformants. Differences in urease activity between wild-type and $f l b A$ mutants of various $H$. pylori strains may be explained by the observations of high mutation frequency leading to genetic variability [51-54] of urease, $f b A$ or nixA or to numerous strain-specific genes [23]. For example, recent studies have found: two different $\operatorname{cag}(+)$ strains [55] exhibiting different effects on interleukin-8 production by gastric epithelial cells; strain differences with respect to urease activity in nix $A$ mutants $[8,56]$; and strain differences in arginase and urease activity (Fig. 2a-e) [25, 42, 57]. Clearly, phenotypic variation of $H$. pylori strains can make it difficult for investigators to make generalisations. Therefore, it is recommended that researchers use multiple $H$. pylori strains to investigate phenotypes of wild-type strains and their corresponding isogenic mutants because misleading or premature conclusions might be reached with only one strain.

This study confirmed the original observation of Schmitz et al. [27] that $f l b A$ is required for $H$. pylori motility and extended it by using more strains and by employing a transparent soft agar containing F-12, a chemically defined medium that supports the growth of H. pylori [38]. The homologous gene $f h A$ is likewise required for motility in $P$. mirabilis [58]. Because inhibition of $H$. pylori urease activity by urease inhibitors abolishes motility and chemotaxis through a viscous medium, the proton motive force required for flagellar movement may be generated by the hydrolysis of urea $[15,59-61]$. Indeed, urease-negative H. pylori mutants fail to swarm on motility agar [61]. These data, taken together with those of the present study, suggest that $f l b A$ alters urease activity in both $H$. pylori and $P$. mirabilis and provides a crucial link between two virulence attributes in both human pathogens urease and motility.

The $f b A$ gene was required for $H$. pylori to colonise gerbils. This is the first demonstration of a specific flagellar biosynthesis gene being required for $H$. pylori colonisation of gerbils. One other study suggested that motility is important for colonisation, but the aflagellate variant was of an undefined mutation, was not isogenic with the wild-type strain, and the mutation could potentially be reversible [37]. Notably, no lesions were observed in the antrum of gerbils inoculated with the $f b A$ mutant, whereas lesions of gastritis were common in gerbils infected with wild-type $H$. pylori.

The H. pylori strains used for the gerbil study were SS1 and the isogenic $f l b A$ mutant, which have identical urease activities. Thus, the lack of colonisation by the $f b A$ mutant was not due to altered urease activity. Attempts to complement the mutant have so far been unsuccessful. Other $H$. pylori mutants that affect flagellar biosynthesis are likewise severely attenuated in other animal models [34-36], emphasising the important role of motility in enabling $H$. pylori to penetrate the viscous mucous layer to adhere to the gastric epithelial cell surface and avoid the harsh gastric acidity through urease activity.

In summary, the flagellar biosynthesis and regulatory gene $f b A$ was shown to modulate urease of both $H$. pylori and $P$. mirabilis, but this modulation was by distinct mechanisms. $f b A$ was required for motility and for virulence in $H$. pylori.

We thank Susan Harrington, J. Kyle Hendricks and Xin Li for construction of plasmids, Richard Peek and Adrian Lee for providing strains, Sebastian Suerbaum for helpful discussions, Stephen G. Kayes for histology advice and Susan R. Heimer for a critical review of the manuscript. This work was supported in part by Public Health Service grants AI25567 and AI23328 (H.L.T.M.) and postdoctoral fellowships AI10098 (D.J.M.) and DK59709 (T.L.T.) from the National Institutes of Health.

\section{References}

1. Blaser MJ. Helicobacter pylori and the pathogenesis of gastroduodenal inflammation. J Infect Dis 1990; 161: 626-633.

2. Buck GE, Gourley WK, Lee WK, Subramanyan JM, Latimer JM, Di Nuzzo AR. Relation of Campylobacter pyloridis to gastritis and peptic ulcers. J Infect Dis 1986; 153: 664-669.

3. International Agency for Cancer Research. IARC Monographs on the evaluations of cancer risks to humans. Lyon, World Health Organization. 1994: 177-240.

4. Parsonnet J, Friedman GD, Vandersteen DP et al. Helicobacter pylori infection and the risk of gastric carcinoma. $N$ Engl $J$ Med 1991; 325: 1127-1131.

5. McGee DJ, Mobley HLT. Mechanisms of Helicobacter pylori infection: bacterial factors. In: Westblom TU, Czinn SJ, Nedrud JG (eds) Gastroduodenal disease and Helicobacter pylori: pathophysiology, diagnosis and treatment. Current topics in microbiology and immunology, vol 24. Berlin, Springer-Verlag. 
1999: $155-180$

6. McGee DJ, Mobley HLT. Pathogenesis of Helicobacter pylori infection. Cur Opin Gastroenterol 2000; 16: 24-31.

7. Mobley HLT, Island MD, Hausinger RP. Molecular biology of microbial ureases. Microbiol Rev 1995; 59: 451-480.

8. Bauerfeind P, Garner RM, Mobley HLT. Allelic exchange mutagenesis of nixA in Helicobacter pylori results in reduced nickel transport and urease activity. Infect Immun 1996; 64: 2877-2880.

9. McGee DJ, May CA, Garner RM, Himpsl JM, Mobley HLT. Isolation of Helicobacter pylori genes that modulate urease activity. J Bacteriol 1999; 181: 2477-2484.

10. Mobley HLT, Garner RM, Bauerfeind P. Helicobacter pylori nickel-transport gene nixA: synthesis of catalytically active urease in Escherichia coli independent of growth conditions. Mol Microbiol 1995; 16: 97-109.

11. Ferrero RL, Hazell SL, Lee A. The urease enzymes of Campylobacter pylori and a related bacterium. $J$ Med Microbiol 1988; 27: 33-40.

12. $\mathrm{Hu}$ L-T, Mobley HLT. Expression of catalytically active recombinant Helicobacter pylori urease at wild-type levels in Escherichia coli. Infect Immun 1993; 61: 2563-2569.

13. Slonczewski JL, McGee DJ, Phillips J, Kirkpatrick C, Mobley HLT. pH-dependent protein profiles of Helicobacter pylori analyzed by two-dimensional gels. Helicobacter 2000; 5: 240-247.

14. Scott DR, Weeks D, Hong C, Posius S, Melchers K, Sachs G. The role of internal urease in acid resistance of Helicobacter pylori. Gastroenterology 1998; 114: 58-70.

15. Weeks DL, Eskandari S, Scott DR, Sachs G. A H+-gated urea channel: the link between Helicobacter pylori urease and gastric colonization. Science 2000; 287: 482-485.

16. van Vliet AHM, Kuipers EJ, Waidner B et al. Nickelresponsive induction of urease expression in Helicobacter pylori is mediated at the transcriptional level. Infect Immun 2001; 69: 4891-4897.

17. Mobley HLT, Warren JW. Urease-positive bacteriuria and obstruction of long-term urinary catheters. J Clin Microbiol 1987; 25: 2216-2217.

18. Różalski A, Sidorczyk Z, Kotełko K. Potential virulence factors of Proteus bacilli. Microbiol Mol Biol Rev 1997; 61: $65-89$.

19. Warren JW, Tenney JH, Hoopes JM, Muncie HL, Anthony WC. A prospective microbiologic study of bacteriuria in patients with chronic indwelling urethral catheters. $J$ Infect Dis 1982; 146: 719-723.

20. Jones BD, Lockatell CV, Johnson DE, Warren JW, Mobley HLT. Construction of a urease-negative mutant of Proteus mirabilis: analysis of virulence in a mouse model of ascending urinary tract infection. Infect Immun 1990; 58: 1120-1123.

21. Nicholson EB, Concaugh EA, Foxall PA, Island MD, Mobley HLT. Proteus mirabilis urease: transcriptional regulation by UreR. J Bacteriol 1993; 175: 465-473.

22. Jones BD, Mobley HLT. Proteus mirabilis urease: genetic organization, regulation, and expression of structural genes. $J$ Bacteriol 1988; 170: 3342-3349.

23. Alm RA, Ling L-SL, Moir DT et al. Genomic-sequence comparison of two unrelated isolates of the human gastric pathogen Helicobacter pylori. Nature 1999; 397: 176-180.

24. Tomb J-F, White O, Kerlavage AR et al. The complete genome sequence of the gastric pathogen Helicobacter pylori. Nature 1997; 388: 539-547.

25. Mobley HLT, Cortesia MJ, Rosenthal LE, Jones BD. Characterization of urease from Campylobacter pylori. J Clin Microbiol 1988; 26: 831-836.

26. Island MD, Mobley HLT. Proteus mirabilis urease: operon fusion and linker insertion analysis of ure gene organization, regulation, and function. J Bacteriol 1995; 177: 5653-5660.

27. Schmitz A, Josenhans C, Suerbaum S. Cloning and characterization of the Helicobacter pylori $\mathrm{AbA}$ gene, which encodes for a membrane protein involved in coordinated expression of flagellar genes. J Bacteriol 1997; 179: 987-997.

28. Plano GV, Barve SS, Straley SC. LcrD, a membrane-bound regulator of the Yersinia pestis low-calcium response. J Bacteriol 1991; 173: 7293-7303.

29. Andrews GP, Maurelli AT. mxiA of Shigella flexneri 2a, which facilitates export of invasion plasmid antigens, encodes a homolog of the low-calcium response protein, LcrD, of Yersinia pestis. Infect Immun 1992; 60: 3287-3295.
30. Galán JE, Ginocchio C, Costeas P. Molecular and functional characterization of the Salmonella invasion gene invA: homology of InvA to members of a new protein family. $J$ Bacteriol 1992; 174: 4338-4349.

31. Ginocchio CC, Galán JE. Functional conservation among members of the Salmonella typhimurium InvA family of proteins. Infect Immun 1995; 63: 729-732.

32. Plano GV, Straley SC. Multiple effects of $\operatorname{lcrD}$ mutations in Yersinia pestis. J Bacteriol 1993; 175: 3536-3545.

33. Fleiszig SMJ, Arora SK, Van R, Ramphal R. FlhA, a component of the flagellum assembly apparatus of Pseudomonas aeruginosa, plays a role in internalization by corneal epithelial cells. Infect Immun 2001; 69: 4931-4937.

34. Eaton KA, Morgan DR, Krakowka S. Motility as a factor in the colonisation of gnotobiotic piglets by Helicobacter pylori. J Med Microbiol 1992; 37: 123-127.

35. Eaton KA, Suerbaum S, Josenhans C, Krakowka S. Colonization of gnotobiotic piglets by Helicobacter pylori deficient in two flagellin genes. Infect Immun 1996; 64: 2445-2448.

36. Kim JS, Chang JH, Chung SI, Yum JS. Molecular cloning and characterization of the Helicobacter pylori fliD gene, an essential factor in flagellar structure and motility. $J$ Bacteriol 1999; 181: 6969-6976.

37. Iwao E, Hirayama F, Takagai S, Yokoyama Y, Ikeda Y. Virulence factors of Helicobacter pylori affecting its gastric colonization in Mongolian gerbils. J Gastroenterol 1999; 34 Suppl XI: $47-54$.

38. Testerman TL, McGee DJ, Mobley HLT. Helicobacter pylori growth and urease detection in the chemically-defined medium Ham's F-12 nutrient mixture. J Clin Microbiol 2001; 39: 3842-3850.

39. Ausubel FM, Brent R, Kingston RE et al. (eds). Current protocols in molecular biology. New York, John Wiley \& Sons 1995.

40. Sambrook, J, Fritsch EF, Maniatis T. Molecular cloning: a laboratory manual, 2nd edn. Cold Spring Harbor, NY, Cold Spring Harbor Laboratory. 1989.

41. McAllister CF, Stephens DS. Analysis in Neisseria meningitidis and other Neisseria species of genes homologous to the FKBP immunophilin family. Mol Microbiol 1993; 10: 13-23.

42. McGee DJ, Radcliff FJ, Mendz GL, Ferrero RL, Mobley HLT. The Helicobacter pylori rocF is required for arginase activity and acid protection in vitro but is not essential for in vivo colonization of mice or for urease activity. J Bacteriol 1999; 181: 7314-7322.

43. Miller JH. Experiments in molecular genetics. Cold Spring Harbor, NY, Cold Spring Harbor Laboratory. 1977: 352-354.

44. Josenhans C, Eaton KA, Thevenot T, Suerbaum S. Switching of flagellar motility in Helicobacter pylori by reversible length variation of a short homopolymeric sequence repeat in $f i P$, a gene encoding a basal body protein. Infect Immun 2000; 68 : 4598-4603.

45. Hu L-T, Foxall PA, Russell R, Mobley HLT. Purification of recombinant Helicobacter pylori urease apoenzyme encoded by ure $A$ and ureB. Infect Immun 1992; 60: 2657-2666.

46. Nixon DE, Moyer TP, Squillace DP, McCarthy JT. Determination of serum nickel by graphite furnace atomic absorption spectrometry with Zeeman-effect background correction: values in a normal population and a population undergoing dialysis. Analyst 1989; 114: 1671-1674.

47. Sunderman FW, Crisostomo MC, Reid MC, Hopfer SM, Nomoto S. Rapid analysis of nickel in serum and whole blood by electrothermal atomic absorption spectrophotometry. Ann Clin Lab Sci 1984; 14: 232-241.

48. Templeton DM, Sunderman FW, Herber RF. Tentative reference values for nickel concentrations in human serum, plasma, blood, and urine: evaluation according to the TRACY protocol. Sci Total Environ 1994; 148: 243-251.

49. Sunderman FW, Hopfer SM, Crisostomo MC, Stoeppler M. Rapid analysis of nickel in urine by electrothermal atomic absorption spectrophotometry. Ann Clin Lab Sci 1986; 16: 219-230.

50. Soriano A, Hausinger RP. GTP-dependent activation of urease apoprotein in complex with the UreD, UreF, and UreG accessory proteins. Proc Natl Acad Sci USA 1999; 96: $11140-11144$

51. Akopyants NS, Fradkov A, Diatchenko L et al. PCR-based subtractive hybridization and differences in gene content among strains of Helicobacter pylori. Proc Natl Acad Sci USA 1998; 95: 13108-13113. 
52. Achtman M, Azuma T, Berg DE et al. Recombination and clonal groupings within Helicobacter pylori from different geographical regions. Mol Microbiol 1999; 32: 459-470.

53. Kersulyte D, Chalkauskas H, Berg DE. Emergence of recombinant strains of Helicobacter pylori during human infection. Mol Microbiol 1999; 31: 31-43.

54. Suerbaum S, Maynard Smith J, Bapumia K et al. Free recombination within Helicobacter pylori. Proc Natl Acad Sci USA 1998; 95: 12619-12624.

55 Eaton KA, Kersulyte D, Mefford M, Danon SJ, Krakowka S, Berg DE. Role of Helicobacter pylori cag region genes in colonization and gastritis in two animal models. Infect Immun 2001; 69: 2902-2908

56. Hendricks JK, Mobley HLT. Helicobacter pylori ABC transporter: effect of allelic exchange mutagenesis on urease activity. J Bacteriol 1997; 179: 5892-5902.

57. Dunn BE, Campbell GP, Perez-Perez GI, Blaser MJ. Purification and characterization of urease from Helicobacter pylori. J Biol Chem 1990; 265: 9464-9469.

58. Gygi D, Bailey MJ, Allison C, Hughes C. Requirement for FlhA in flagella assembly and swarm-cell differentiation by
Proteus mirabilis. Mol Microbiol 1995; 15: 761-769.

59. Nakamura H, Yoshiyama H, Takeuchi H, Mizote T, Okita K, Nakazawa T. Urease plays an important role in the chemotactic motility of Helicobacter pylori in a viscous environment. Infect Immun 1998; 66: 4832-4837.

60. Yoshiyama H, Nakamura H, Kimoto M, Okita K, Nkazawa T. Chemotaxis and motility of Helicobacter pylori in a viscous environment. J Gastroenterol 1999; 34 Suppl 11: 18-23.

61. Yoshiyama H, Nakazawa T. Unique mechanism of Helicobacter pylori for colonizing the gastric mucus. Microbes Infect 2000; 2: $55-60$.

62. Simons RW, Houman F, Kleckner N. Improved single and multicopy lac-based cloning vectors for protein and operon fusions. Gene 1987; 53: 85-96.

63. Wang RF, Kushner SR. Construction of versatile low-copynumber vectors for cloning, sequencing and gene expression in Escherichia coli. Gene 1991; 100: 195-199.

64. Gherardini FC, Hobbs MM, Stam M LV, Bassford PJ. Complementation of an Escherichia coli proC mutation by a gene cloned from Treponema pallidum. J Bacteriol 1990; 172: 2996-3002. 